Última DÉCADA, N56, OCTUBRE 2021, PP. 213-243

\title{
FUTURO INCIERTO EN UN MUNDO INABARCABLE: RENTABILIZACIÓN POLÍTICA DE MEMES EN TIEMPOS DE COVID-19
}

\author{
SANDRA ITURRIETA OLIVARES ${ }^{1}$ \\ JONATHAN FRANCO ARAYA ${ }^{2}$
}

\begin{abstract}
RESUMEN
Las discusiones sobre la cultura del éxito en sociedades neoliberales que mandata la gestión individual de la incertidumbre, del miedo al futuro y del agobio existencial, fueron abruptamente teñidas por la llegada del Covid-19, situando tales emociones en un lugar aún más preponderante. Un medio de expresión de estas emociones son los memes, que cumplen una función catalizadora, a la vez que son unidades culturales y discursivas cuyos contenidos podrían ser rentabilizados políticamente. El presente artículo discute aquello analizando algunas de estas publicaciones en redes sociales, proponiendo que tales contenidos representan campos en disputa para las ciencias sociales contemporáneas.
\end{abstract}

PALABRAS CLAVES: MEMES DE INTERNET, SUBJETIVIDADES, RENTABILIZACIÓN

POLÍTICA DEL TEMOR.

${ }^{1}$ Doctora en Ciencias Sociales, Universidad de Granada, España. Postdoctorada en el estudio de las ideas, Instituto de Estudios Avanzados, Universidad de Santiago de Chile. Magíster en el análisis de los problemas sociales de las sociedades avanzadas, Universidad de Granada, España. Académica Escuela de Trabajo Social, Pontificia Universidad Católica de Valparaíso, Chile. Correo electrónico: sandra.iturrieta@pucv.cl

${ }^{2}$ Estudiante de pregrado, Escuela de Trabajo Social, Pontificia Universidad Católica de Valparaíso, Chile. Ayudante de Cátedra Métodos de Investigación para Trabajo Social I, Escuela de Trabajo Social, Pontificia Universidad Católica de Valparaíso, Chile. Integrante del Núcleo Semilla correspondiente al Núcleo de Investigación sobre el Presente y Futuro de las Profesiones de la Pontificia Universidad Católica de Valparaíso, Chile. Correo electrónico: jonathanfrancoaraya@gmail.com 


\title{
FUTURO INCERTO EM UM MUNDO INSONDÁVEL: LUCRATIVIDADE POLÍTICA DOS MEMES EM TEMPOS DE COVID-19
}

\begin{abstract}
RESUMO
As discussões sobre a cultura do sucesso nas sociedades neoliberais que exige a gestão individual da incerteza, do medo do futuro e da opressão existencial, foram abruptamente coloridas com a chegada do COVID-19, colocando tais emoções em um lugar ainda mais proeminente. Uma forma de expressar essas emoções são os memes, que desempenham um papel catalítico, além de serem unidades culturais e discursivas cujos conteúdos podem ser politicamente lucrativos. Este artigo discute isso analisando algumas dessas publicações nas redes sociais, propondo que tais conteúdos representam campos em disputa pelas ciências sociais contemporâneas.
\end{abstract}

PALAVRAS-CHAVE: MEMES DA INTERNET, SUBJETIVIDADES, LUCRATIVIDADE POLÍTICA DO MEDO

\section{UNCERTAIN FUTURE IN AN UNFATHOMABLE WORLD: POLITICAL PROFITABILITY OF MEMES IN TIMES OF COVID-19}

\begin{abstract}
The discussions about the culture of success in neoliberal societies that mandates the individual management of uncertainty, fear of the future and existential overwhelm, were abruptly colored by the arrival of COVID-19, placing such emotions in an even more prominent place. A means of expressing these emotions are memes, which play a catalytic role, as well as being cultural and discursive units whose contents could be politically profitable. This article discusses this by analyzing some of these publications on social networks, proposing that such contents represent fields in dispute for contemporary social sciences.
\end{abstract}

KEYWORDS: INTERNET MEMES, SUBJECTIVITIES, POLITICAL PROFITABILITY OF FEAR 


\section{ANTECEDENTES}

Con anterioridad al año 2020, la incertidumbre que permea diversas dimensiones de la vida cotidiana fue uno de los temas preponderantes de las discusiones sociológicas. Según los sociólogos de la modernidad, Giddens (1996), Beck (2002) y Bauman (2008), tal incertidumbre sería provocada por la «destradicionalización» de la vida cotidiana, debido al surgimiento de mayores espacios de libertad (Beck, 2002), y a las opciones múltiples que ofrecen las sociedades contemporáneas (Giddens, 1996). Tal incertidumbre se refiere al modo de interpretar una situación y elaborar una respuesta que permita obtener los resultados pretendidos. En tal sentido, la incertidumbre sería confusión experimentada como inquietud y agobio (Giddens, 1996).

Según estos autores, a la noción de incertidumbre se opone la de confianza, que es crucial para el desarrollo de la personalidad, como para la potenciación de aspectos distintivos y específicos personales. De modo que la confianza está directamente referida a la consecución de un cierto sentido primario de seguridad ontológica, que permite la interacción con los sistemas abstractos que vacían a la vida cotidiana de su contenido tradicional y establecen influencias globales. Por tanto, la confianza defiende al sí-mismo en sus contactos con la realidad cotidiana, de acontecimientos que, de ser contemplados en toda su magnitud, producirían parálisis de la voluntad o vivencias de abatimiento. La confianza es, entonces, una especie de escudo protector de amenazas y peligros potenciales contenidos en las actividades cotidianas (Giddens, 1996). No obstante, la incertidumbre respecto del futuro, la fragilidad de la posición social y la inseguridad existencial son elementos omnipresentes en las cotidianeidades actuales, por ello la incertidumbre suele centrarse en objetivos más cercanos de la vida cotidiana, dirigiéndose a los asuntos relacionados con la seguridad personal. Pese a ello, la tarea de afrontarla ha sido dejada en manos de iniciativas y esfuerzos locales; privatizada y transferida en gran medida a cada persona en términos individuales (Bauman, 2008). 


\section{FUTURO COMO INCERTEZAS, AGOBIOS Y MIEDOS}

Conjuntamente con la pérdida de referentes institucionales y de aquellos basados en las tradiciones, los sistemas de ordenamiento social de corte neoliberal, en vastos lugares del orbe, han ido carcomiendo paulatinamente cada uno de los pilares básicos de la seguridad existencial, con que cada persona interpreta subjetivamente su futuro, extendiéndose un manto de incertezas, agobios y miedos, los que, conforme a tal modelo de desarrollo, deben ser enfrentados de modo individual y además con éxito. Así, la visión de una «vida mejor» se ha desacoplado de la idea de futuro, instalándose en su lugar incertezas, agobios y miedos, ya que cada vez más las personas son confrontadas a «un mundo que ostenta una cantidad inabarcable de líneas de ruptura, saltos y abismos, entre los cuales nadie sabe ya muy bien cómo orientarse» (Beck, 2006: 15). El futuro se ve como una pluridimensionalidad que no puede ser interpretada a través de los modelos explicativos tradicionales. «Existen muchos más enigmas que soluciones y, si nos fijamos bien, las propias soluciones se revelan como costales repletos de enigmas» (Beck, 2006: 15). Ello ha sido exacerbado en el actual contexto marcado por la presencia del Covid-19 en nuestras sociedades, en que los manejos políticos de la pandemia, en términos generales en América Latina, han sido poco claros para la ciudadanía.

Todos los factores anteriormente señalados producen inseguridad existencial en las juventudes, no solo en el sentido de la pérdida de confianza entre las personas y en las instituciones claves del mundo industrializado, sino que además cobran sentido los conceptos de ambivalencia y vacío. La ambivalencia se refiere a la simultaneidad de sentimientos generados por la pérdida de la univocidad, es decir, por la pluralidad de sentidos y significados posibles, particularmente en tiempos socio-sanitariamente convulsionados, lo que provoca incertezas intelectuales y políticas. Mientras que el vacío alude a que instituciones valiosas de Occidente han perdido sus fundamentos históricos, 
en que las personas son activamente políticas, tensionando y deslegitimando a las instituciones autocentradas, con una total pérdida de confianza en ellas. Ambos conceptos, ambivalencia y vacío, tomados conjuntamente significan apertura desde el punto de vista intelectual y político (Beck, 2006) y conjuntamente retroalimentan la inseguridad existencial respecto de la vida futura en el actual contexto.

Esta inseguridad existencial es vivida como una especie de miedo o agobio frente a algo indefinido e incontrolable, y sería el resultado de un carácter orientado externamente, lo que es particularmente frecuente en la etapa de la juventud, ya que en esta etapa la vida se orienta fundamentalmente en función de las expectativas que tienen otras personas sobre sí, en un contexto donde todas las posibilidades están abiertas y todo es relevante, porque todo hecho debe tener un sentido, y contribuir a alcanzar un objetivo vital externamente perfilado (Bude, 2014).

En el actual contexto sociosanitario, y en sociedades con relatos meritocráticos como las latinoamericanas en general, donde el reverso del ascenso es el descenso social, el agobio y miedo al futuro dice relación no solo con una mirada pesimista respecto de que las futuras generaciones puedan mantener, o superar la posición y reconocimiento social alcanzado por sus generaciones precedentes - lo que representa un ideal de vida socialmente enraizado en tales culturas-, sino que además en este tipo de sociedades, el miedo reside en la pérdida del valor de las credenciales educativas, ya que a pesar de contar con vastos y sólidos certificados, las personas jóvenes se sienten desprotegidas y vulnerables frente al sistema de ordenamiento social, que impone una agencia individual.

De este modo, el miedo se agencia en comparación con un grupo de referencia. Surge frente a la posibilidad de obtener muy poco de aquello socialmente preciado. Por tanto, el miedo es un temor por vivir exclusión y 
degradación. Así, también es posible sentir agobio o miedo al futuro, porque hasta ahora todo ha funcionado bien. Ello se acrecienta en el actual contexto en que priman los relatos sobre transformaciones sociales futuras, cuando el temor por la conservación o transformación de la posición propia en el sistema va unido al agobio por el colapso de todo el sistema de posiciones legítimas o indeseables (Bude, 2014: 54) A ello se suma la irrupción del Covid-19 en nuestras cotidianeidades, que tiñe de temor las vidas no solo por un agente patógeno, sino además porque representa un desestabilizador de las economías y de los modos de vida habituales, exacerbando los niveles de incertidumbre colectiva e individual, que forman parte de las subjetividades actuales descentradas de sus rutinas, lo que es particularmente relevante en el caso de las juventudes dado que la construcción de confianza, como protección frente a amenazas y peligros cotidianos, está en construcción.

\section{FUNCIÓN SOCIAL DEL MIEDO}

En tiempos de Covid-19, de incertezas, destradicionalización, desconfianzas y de inseguridad existencial frente al futuro, que es visto como una pluridimensionalidad con amplitud de posibilidades, el miedo «quizá sea el único factor a priori de las sociedades modernas sobre el que se pueden poner de acuerdo todos los miembros de la sociedad: el miedo es el principio que tiene una validez absoluta una vez que todos los demás principios se han vuelto relativos» (Bude, 2014:7 siguiendo a Luhmann). De manera que, para relacionarse, quienes componen este tipo de sociedades se comunican empleando conceptos de miedo: enfermedad/recuperación/muerte; exclusión/inclusión; riesgos ambientales/de pérdida del trabajo; mantención del coronavirus SARS-CoV-2/cambios permanentes de formas de vivir/pérdida de la libertad; futuro incierto; pobreza como amenaza siempre latente; inseguridad existencial, etcétera, lo que se traduce en exigencias de éxito y, por tanto, en agobio. 
En las sociedades neoliberales ha habido entonces un cambio en el modo de integración social, pasando de la promesa de ascenso a la amenaza de exclusión, en que son centrales los conceptos de apertura y desarrollo, tanto en el plano de lo individual como de lo social, donde el éxito es un mandato universal. No obstante, «la delirante obsesión por optimizar sólo tapa una indigencia existencial» (Bude, 2014: 51), ya que la confesión pública del miedo individual no es algo socialmente deseable, sino que solo es aceptable como argumento para oponerse a algo en nombre de terceras personas. De allí que el agobio se constituya en una vía de expresión de inseguridad existencial y de miedo al futuro.

El agobio y miedo se hacen más intensos cuanto más inconcretas sean sus causas (Laca, 2011). Ambas corresponden a emociones profundas y ampliamente extendidas en las sociedades actuales, lo que potencia que las poblaciones acepten diferentes medidas ofrecidas por los Estados, que parezcan protegerles de sus causas (Laca, 2011). Por tanto, los gobiernos rentabilizan el miedo «como una nueva y poderosa fuente de legitimación del poder, cuando otras fuentes como la protección social y la redistribución de la riqueza han quedado muy debilitadas después de tres décadas de políticas neoliberales» (Laca, 2011: 16). En tal sentido, las tecnologías de información y comunicación cumplen un rol central reordenando prioridades en la sociedad del miedo: la exclusión creciente y el aumento de la pobreza se presentan como menos urgentes, que la guerra contra el terrorismo, o contra la delincuencia organizada (Laca, 2011). En el actual contexto, la lucha contra el Covid-19 es presentada como una batalla imposible de ganar, porque se trata de un ente poco conocido y con un poderío tal, que pareciera ser incontrolable, más aún cuando las responsabilidades de ello recaen fundamentalmente en las personas en términos individuales, y no en políticas públicas efectivas, que tengan como centro el bienestar humano, y no el desarrollo económico en cuanto tal. De allí que se abre la posibilidad a la rentabilización política del miedo a la pandemia, estando las personas jóvenes en 
el centro de la susceptibilidad, dada la gestión individual del bienestar, y que la construcción de la confianza y sus posibilidades aún se encuentran en desarrollo en esta etapa del ciclo vital.

\section{LOS MEMES COMO CONSTRUCTORES DE SUBJETIVIDADES}

Si concordamos con los planteamientos de Foucault (1994) referidos a que cada momento histórico propone o prescribe a los individuos elementos para fijar su subjetividad, conservarla o transformarla en razón de un cierto número de fines, debido a las relaciones de dominio de sí, sobre sí, o de conocimiento de sí por sí mismo, más allá de la idea de un «individuo disciplinario» (Foucault, 1992); y si además consideramos que los procesos de subjetivación se articulan a través del lenguaje (Guattari, 1988), y que «no es sólo una cuestión de ideas o de significaciones por medio de enunciados significantes. (...) Se trata de sistemas de conexión directa entre las grandes máquinas productivas, las grandes máquinas de control social y las instancias psíquicas que definen la manera de percibir el mundo» (Guattari y Rolnik 2006: 41), es innegable la incidencia de las tecnologías de comunicación e información, y con ellas de las redes sociales, en la estructuración de las subjetividades con las que las personas interactúan, por tanto, dichas tecnologías desempeñan un papel relevante en las configuraciones emocionales y políticas de las sociedades contemporáneas. Asimismo, en el actual contexto de Covid-19 se ha evidenciado su impacto en la forma en que se concibe actualmente el tiempo y el espacio, donde la inmediatez de diversos mecanismos de intercambio de información es parte de la cotidianeidad de amplios sectores de la población mundial, y en particular de las juventudes. Se han abierto nuevos canales de intercambio, nuevas formas de socializar: la simultaneidad se identifica como una característica epocal. Asimismo, las formas en que el intercambio social y cultural se produce también han variado, y los contactos virtuales expresados a través de memes son 
testimonios de aquello.

El concepto de meme fue difundido en la década del 70 por Richard Dawkins (1985), quien lo define como una unidad de difusión, reproducción o replicación cultural. Se conciben como una unidad que «transmite un suceso, material o idea — que pueden tener la forma de una imagen, video, música, frase o broma - que es seleccionada, modificada y transmitida de persona a persona en Internet. Gracias a la capacidad de Internet de transmitir información de forma casi instantánea y precisa, estos memes pueden difundirse masivamente, principalmente por páginas de redes sociales y para compartir archivos» (García, 2014: 2).

Para que dichos memes puedan ser interiorizados y difundidos deben poseer cualidades tales como inmaterialidad e inmediatez (García, 2014), además de fecundidad, fidelidad y longevidad (Dawkins, 1985). La fecundidad se refiere a qué tan aceptable es la idea que se transmite, siendo - en la mayoría de los casos- poseedores de un elemento humorístico que, sumado a que habitualmente son representaciones de la vida cotidiana, logran alivianar el agobio, miedo al futuro o inseguridad existencial presentes en las cotidianeidades, por tanto, logran tal fecundidad.

En cuanto a la fidelidad, puede decirse que los memes están sujetos a constantes cambios y mutaciones en el proceso de difusión. No obstante, la idea que se difunde, si bien puede tener ciertas distinciones de orden contextual, apunta a un sentido determinado que, sin embargo, no es rígido. Por su parte, el criterio de longevidad tiene menor importancia debido a que un meme puede durar un tiempo determinado, pero al mismo tiempo ir variando en cuanto a su significante. De modo que los memes tienen un marcado carácter histórico, en cuanto a cómo van contribuyendo a producir y difundir ideas sobre la cotidianeidad, impactando en las subjetividades de quienes los utilizan.

Así, los memes serían unidades culturales que se difunden entre las 
personas, articulándose como discursos. Es decir, como aquel cuerpo de reglas y saberes anónimos definidos históricamente, con los cuales los sujetos - al constituirse como tales - conciben la realidad (Foucault, 1979). Por tanto, los memes como mecanismos de poder discursivo devienen en la emergencia de nuevas subjetividades, especialmente en aquellas personas que constantemente realizan este tipo de contactos virtuales, tales como las juventudes, quienes se constituirían en sujetos «sujetados» y dependientes de las formas en que ese poder se manifiesta (Apreda, 2004). Sin embargo, tales discursos y las verdades que las diversas subjetividades legitiman son dinámicas e históricamente situadas, ya que el sujeto «es una forma, y esta forma no es sobre todo ni siempre idéntica a sí misma [...] Existen, sin duda, relaciones e interferencias entre estas diferentes formas de sujeto» (Foucault, 1994: 123).

De manera que las incertidumbres, agobios y miedos al futuro ya no se mantienen contenidos en pequeños espacios o núcleos de socialización, sino que la característica «viral» de los memes, como mecanismos de poder discursivo, contiene dentro de sí tales formas de significar la cotidianeidad y el futuro. En tal sentido, no se trata de qué tan verdaderos sean dichos discursos, ya que la era de nuevas tecnologías de información y comunicación trae consigo el declive de «La Verdad» como un asunto monopólico de los poderes ya instaurados (Bauman, 2017), aun cuando tal polivocalidad no necesariamente implique emancipación de las personas. La intrincada red de relaciones humanas, abierta en un vértigo de nuevos canales y formas comunicativas, hace evidente lo que Foucault (1992) afirmó respecto del poder —o más bien de los poderes-, que se manifiesta y ejerce de forma reticular, heterogénea y dispersa entre las personas, donde el ejercicio del poder no es sino la forma en que las relaciones atravesadas por este producen diversas subjetividades.

En consecuencia, en sociedades neoliberales donde los Estados cada vez más están al servicio del mercado y de intereses económicos, y son cada vez más 
vigilantes de las vidas cotidianas de las personas, los memes tendrían una doble función: como expresión de subjetividades en búsqueda de seguridad existencial $\mathrm{y}$ de gestión del agobio frente a una emoción profunda y ampliamente compartida, como lo es el agobio y temor al futuro. Por otra parte, como medio para rentabilizar una nueva fuente de legitimación del poder político, en que el miedo al futuro y el agobio existencial expresados en esos contactos virtuales serían puestos como ejes narrativos centrales por la clase política dominante, quienes usarían las descripciones de las diversas cotidianeidades, expresadas en redes sociales, y en el caso que nos ocupa, en los memes, para rentabilizar tal temor al futuro y agobio existencial como una forma de legitimación de su poder político. Ello se evidencia en el compromiso central del programa de gobierno con el que el actual presidente de Chile desarrolló su campaña política, rumbo a la presidencia del país en el año 2018: «Nuestras prioridades serán las prioridades de la gente. Nuestra aspiración es resolver sus problemas, potenciar sus oportunidades, ampliar sus libertades, mitigar sus temores y colaborar en el cumplimiento de sus sueños» (Vota Inteligente, 2018). La idea de mitigación del temor ha sido ampliamente explotada durante los tiempos de pandemia vividos en Chile: «Esta pandemia provoca privaciones, temores y angustias a muchas familias chilenas. Las cuarentenas y los aislamientos también provocan privaciones, temores y muchas veces soledad, por no poder estar con nuestros seres queridos y no poder vivir nuestras vidas con normalidad» (Sebastián Piñera, 2020). Las ideas de oportunidades, libertades, temores, angustias, sueños y soledad están recurrentemente presentes en los memes con los que las personas jóvenes intersubjetivamente se comunican. 


\section{Metodología}

Con la finalidad de producir datos empíricos que permitieran discutir los enunciados anteriores, se llevó a cabo una revisión de diversas redes sociales dedicadas a publicar diariamente contenido. Se optó por analizar los memes publicados en Instagram, considerando que, según los datos del último informe realizado por las plataformas de gestión digital We are Social y Hootsuite, en su reporte anual «Digital 2021: Global digital overview», la red social Instagram es reconocida como una de las plataformas con las mayores audiencias, con alrededor de 1,2 billones de personas en todo el mundo (Kemp, 2021). Además, se caracteriza por su formato que permite compartir y difundir contenidos audiovisuales de consumo fácil (como los reels, stories, imágenes, realizar encuestas rápidas, entre otras funciones), comentar publicaciones, seguir (y ser seguido), condiciones aptas para la proliferación y difusión de gran cantidad de ideas a través de memes. También es fuente de entretenimiento e información, sobre todo en aquellos usuarios más jóvenes, los que representan más del 70\% de la audiencia de la plataforma (Kemp, 2021). Asimismo, los datos revelados por el informe «Tendencias en redes sociales 2021», realizado por las plataformas de desarrollo y gestión digital Hubspot y Talk Walker, indican que quienes se encuentran en la etapa de la juventud crean y comparten una mayor cantidad de memes, cuyas menciones han aumentado desde el año 2019 en adelante, llegando a su cúspide en abril del año 2020 (Halligan y Shah, 2021).

Con la finalidad de captar la creación y consumo de contenidos referidos a imágenes que reflejen las subjetividades con las que estas personas jóvenes imaginan el futuro, se realizó la búsqueda de publicaciones que contuvieran la palabra «futuro» como tendencia o hashtag. El contenido revisado y seleccionado desde diversos perfiles — personales y dedicados a la difusión de memes - fue publicado entre el primer trimestre del año 2020 y el primer trimestre de 2021. Sobre la base de los criterios de fecundidad (aceptación) y 
fidelidad (mutabilidad), se seleccionaron aquellas imágenes que tuvieran una mayor cantidad de «me gusta», y comentarios que contuvieran expresiones e interacciones de otras personas jóvenes usuarias, que fueran significativas para el análisis en el marco del futuro como incertezas, agobios y miedos.

Fueron seleccionadas dos tipos de publicaciones: aquellas cuyo contenido hace referencia a experiencias de la vida cotidiana de las personas y las que contienen representaciones explícitas sobre las concepciones en torno al futuro en el actual contexto. Además, se escogieron aquellos comentarios representativos de dichas visiones, identificando, dentro de lo posible, el sexo y rango etario de quienes formulan tales comentarios, a lo que se pudo acceder revisando los perfiles de quienes los han escrito. Dada la información disponible, el sexo fue considerado como hombre/mujer/indeterminado, y el rango etario entre los 16 y 30 años. Cabe mencionar que los memes incluidos en este artículo tenían, hasta el momento de ser consultados, 10.895 contactos virtuales en promedio.

\section{MEMES COMO GESTIÓN DE INCERTIDUMBRES, AGOBIOS Y MIEDOS AL FUTURO}

Al hacer un análisis de cada uno de estos memes, identificando contenidos explícitos y latentes en relación con incertidumbres, agobios y miedos al futuro, y sobre la base de que estas imágenes corresponden a discursos que se difunden entre las personas $y$, por tanto, forman parte de los dispositivos que participan en la construcción de subjetividades, es posible identificar mensajes referidos al agobio con el que las personas jóvenes viven sus cotidianeidades, en que la inseguridad existencial y el miedo se suman a las dificultades propias de la vida en sociedad: 


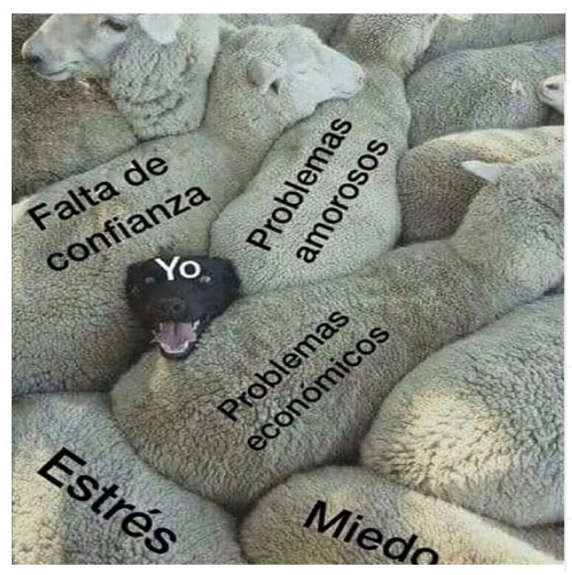

FigURA 1. MEME SOBRE AGOBIO COTIDIANO. INSTAGRAM

La subjetividad que es transmitida por esta imagen es secundada a través de la figura del auxilio frente a la asfixia de la cotidianeidad: «pondré esta foto en el comedor junto con mi inhalador»(Mujer). Entretanto que se sugieren formas de evasión, a través del consumo de drogas: «Pues a comerse un tripi o unas setas, y ver cómo desaparece todo. O mejor dicho, ver cómo aprendes a mandarlo a la mierda xD» (Sexo sin determinar).

Conjuntamente, la sensación de vacío que se entreteje con la cotidianeidad como parte de la inseguridad existencial es compartida a través de una imagen que a su vez entremezcla lo abstracto con lo concreto del diario vivir:

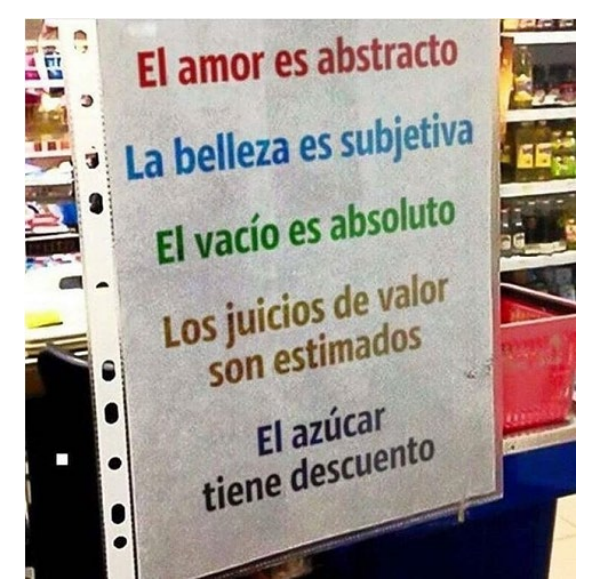

Figura 2. MEME SOBRE VACÍO EXISTENCIAL. INSTAGRAM. 
A través de las interacciones virtuales, se evidencian adhesiones a este mensaje que reafirman la idea de vacío existencial: «Y lo único que cuenta ahí es que el vacío es absoluto» (Hombre). Asimismo, mediante la ironía se transmite incerteza en aquello inmaterial de la vida cotidiana, otorgando importancia solo a lo tangible y no existencial: «¿El azúcar tiene descuento realmente?» (Mujer).

Mientras, el vacío existencial y la ambivalencia generada por la pérdida de univocidad en las sociedades actuales son vividos como desarraigo e incerteza en el futuro:

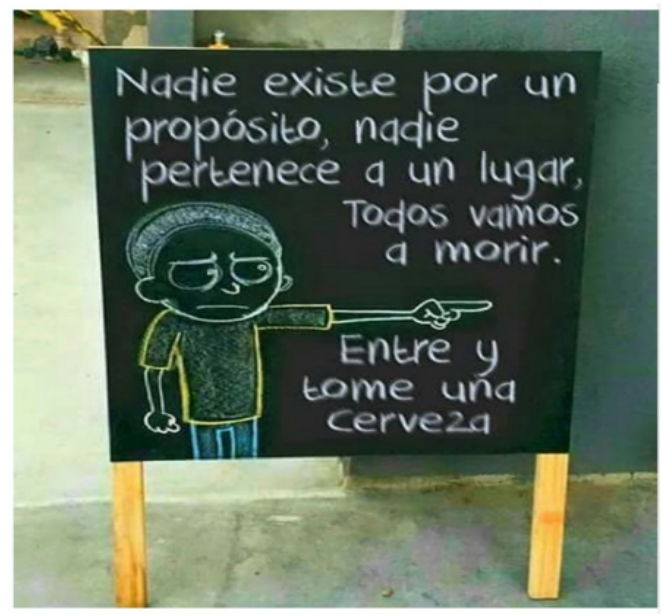

FigurA 3. MEME SOBRE DESARRAIGO E INCERTEZA. INSTAGRAM

Esta frase, acuñada en la serie animada para adultos de la televisión estadounidense Rick and Morty, que varía en la invitación formulada por el meme, ya que originalmente invita a ver televisión, es ratificada por contactos virtuales que, a través del humor, resaltan el desarraigo y un futuro incierto: «Todos vamos a un mismo destino, la muerte jajajaja» (Mujer). Igualmente, el vacío existencial y la evasión de ello se entremezclan con la desconfianza: «Retorcer tu realidad, para no pensar en lo que leíste y seguir creyendo que tienes un propósito. O solamente es un cartel con el objetivo de capturar al lector y que entre a tomar una cerveza para beneficio de quien lo escribió») (Sexo sin determinar). 
Por otra parte, la incertidumbre experienciada como inquietud y agobio, frente a un mundo inabarcable y un futuro pluridimensional e incierto, se expresa a través de un «yo» como figura infantil:

Yo viendo la situación que acontece en el mundo,sin saber que decir...

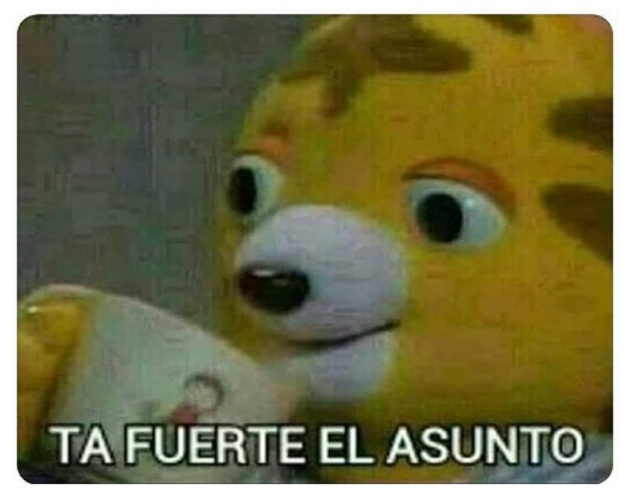

FIGURA 4. MEME SOBRE INCERTIDUMBRE EN EL ACTUAL CONTEXTO. INSTAGRAM

Tal indefensión como sentido ontológico humano es reforzada en las interacciones virtuales: «Pues, que nuestra especie se extinga o evolucione, pero por cómo van las cosas prefiero que nos extingamos todos» (Mujer). Tal desamparo se transmite además como agobio frente a algo incontrolable, por una humanidad cuya arrogancia la ha llevado a un estado de inquietud: «El mundo y el ser humano que se cree prácticamente un dios alterando a la naturaleza, se da cuenta que siempre estará por debajo de ella» (Hombre).

El agobio producido por la idea de futuro incierto y distópico, provocado por los vicios de los sistemas de ordenamiento social vigentes en la actualidad, así como por totalitarismos culturales, conflictos morales, desconfianzas en lo social e institucionalmente instaurado, junto con las incertezas provocadas por los riesgos que conllevan las transformaciones medioambientales y por la presencia del Covid-19 en el mundo, generarían una necesidad de rebeldía personal, que es acallada por el propio sistema social en que cada persona vive 
su cotidianeidad. Ello es representado a través de títulos de películas o de novelas que han sido convertidas en filmes, que permiten trasmitir tales subjetividades:

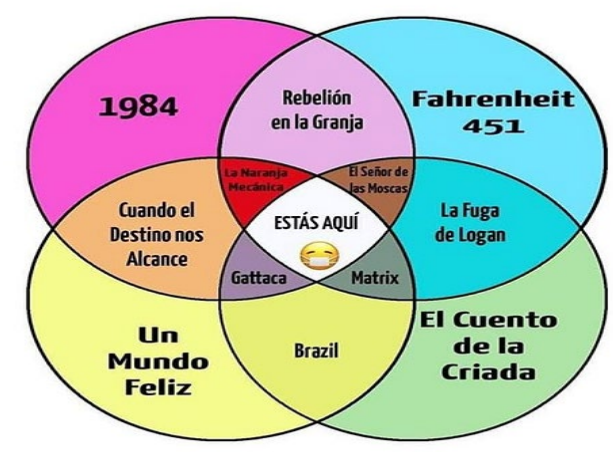

\section{Figura 5. MEME SOBRE AGOBIO SOCIAL. InSTAGRAM}

Esta expresión de agobio genera interacciones en la misma línea discursiva: «mi cabeza va a explotar» (Hombre), o se responde aludiendo a películas, en este caso Matrix: «Tome la pastilla roja, gran hermano» (Mujer). Es decir, se vive la cotidianeidad experimentando una liberación de la opresión impuesta por el sistema social imperante tras haber decidido hacerlo, con poca información y confiando en lo desconocido, puesto que ello permite vivir en un mundo real, aunque con un futuro incierto. Desde otra perspectiva, se transmite la idea de que el agobio existencial es una realidad individual producida en una temporalidad particular: «Somos una línea temporal de tiempo alterna, nuestra propia distopía...» (Hombre).

En tanto que la inseguridad existencial y el miedo al futuro en sociedades con relatos meritocráticos e individualistas forman parte de las subjetividades transmitidas mediante estos contactos virtuales, graficados a través de las calificaciones sobresalientes (entre 9,8 y 10 en una escala de 1 a 10), obtenidas durante el período escolar: 


\section{Todos los que tuvieron calificaciones asi ahora sufren de ansiedad, depresión y les cuesta mantener una relación estable.}
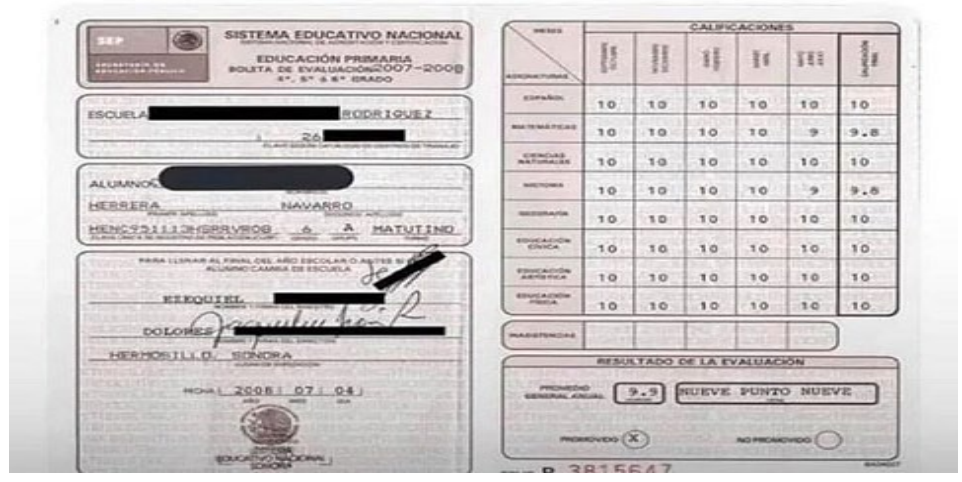

FIGURA 6. MEME SOBRE EXITISMO. INSTAGRAM

Las subjetividades transmitidas a través de este meme refuerzan la idea de una seguridad existencial sustentada externamente, en que el agobio es producido por una expectativa de éxito generada desde el entorno social no necesariamente inmediato: «Es verdad... la gente espera mucho de nosotros y es frustrante no poder» (Mujer). No obstante, el sustento externo de la seguridad existencial es relativizado, aun cuando no se deslegitima el relato exitista: «pero al final tú eres tus demonios y aprendes a amarlos» (Hombre). Conjuntamente, el éxito se valora como una especie de dádiva externamente otorgada: «A mí me cuesta y yo no tenía esas notas. La vida me jodió doble jakaka» (Hombre). Desde otra perspectiva, el agobio existencial se disocia del éxito académico: «Yo no tuve calificación así y tengo todo eso» (Hombre). A la par, se ironiza el relato exitista, pero no se desvincula de la idea de agobio existencial: «Nunca conocí un 9, así que quizás sí, debe ser estresante no ser perfecto» (Hombre).

Mientras tanto, el relato exitista propio de las sociedades neoliberales es vinculado con la idea de un futuro incierto: 


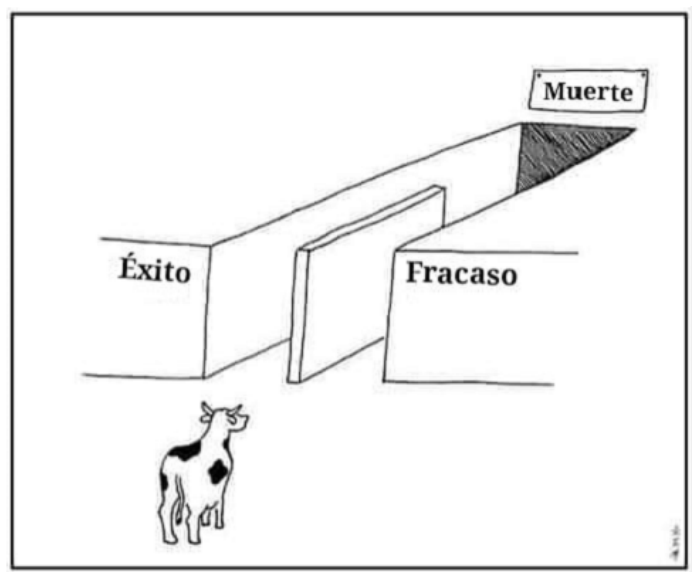

FigURA 7. MEME SOBRE FUTURO INCIERTO. InSTAGRAM

La dicotomía éxito/fracaso, en que la humanidad es representada por un animal que no tiene poder de discernimiento sobre la disyuntiva, y por tanto la única resultante de aquello es la muerte, es secundado por la idea de incertidumbre: «la muerte es la única certeza que tenemos» (Hombre). Mientras que la ironía es puesta al servicio de avalar la inseguridad existencial allí plasmada: «yo habría dibujado un par de árboles y sonrisas en el del éxito. Con todo, una imagen genial» (Hombre).

Por otra parte, la pluridimensionalidad e incertidumbre con la que subjetivamente es interpretado el futuro son vividas como una fuente de tensión que asecha la vida cotidiana, ya que no habría modelos explicativos tradicionales para gestionar la incerteza en el futuro, a lo que se adiciona el mandato social referido a que ello debe ser agenciado de modo individual: 


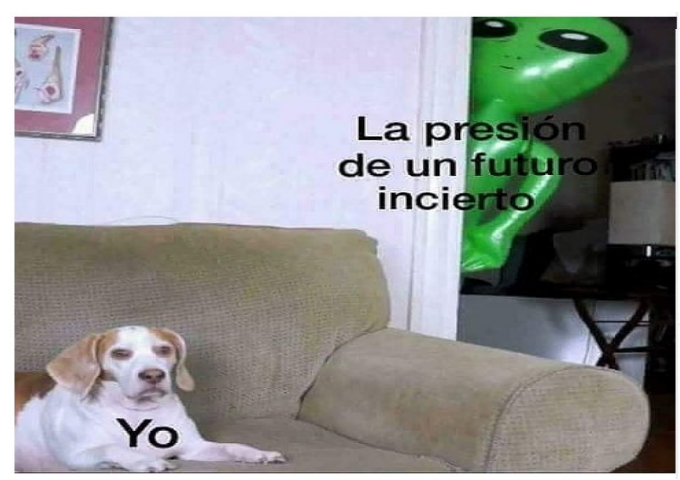

FIGURA 8. MEME SOBRE PRESIÓN POR FUTURO INCIERTO. INSTAGRAM

Los contactos virtuales subscriben con congoja la idea de intimidación por el futuro incierto: «Tan triste pero cierto» (Mujer). No obstante, también ofrecen alivio relativizando la noción de porvenir: «el futuro no existe» (Mujer), o significando con levedad la certeza de vivirlo: «Nah. Me da suda el futuro. Quizás estemos muertos mañana» (Hombre).

Entretanto, la idea apocalíptica sobre el futuro en que la noción de progreso está desacoplada de la felicidad humana es transmitida a través de una imagen, en que se contrastan los años 90 tipificados como el sueño de un futuro dinámico, de progreso y felicidad, con la representación actual de un futuro oscuro:

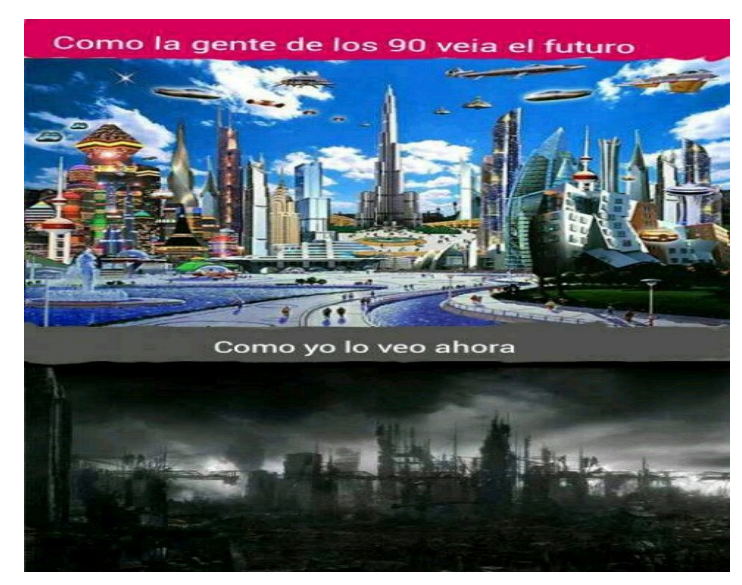

Figura 9. MEME SOBRE FUTURO NEGATIVO. MEMEDRIOD 
Frente a una imagen tan directa de un futuro negativo, los contactos virtuales refutan la idea difundida: «Algo pesimista diría yo» (Hombre). Mientras que negando que el cambio climático sea real, se contradice el mensaje argumentando: «Yo aún creo que nuestro futuro se verá como la primera imagen» (Hombre). No obstante, cuando la imagen difundida es más abstracta y alude a una situación contextual como la crisis sanitaria mundial, por contagio de Covid19, se avala la idea de futuro negativo, lo que se evidencia en estos contactos virtuales:

\section{Año 2060*}

- Abuelo, ¿por qué te lavas las manos

tan seguido?

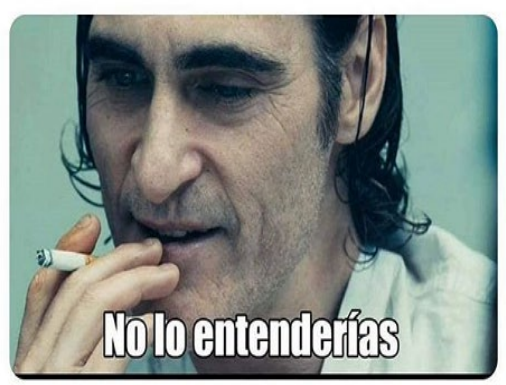

\section{FIGURA 10. COVID-19 Y FUTURO. INSTAGRAM}

Surgen entonces interacciones, tales como: «Si es qué hay agua para ese entonces» (Mujer). Se muestra la pérdida de confianza en el futuro, sustentada en la desesperanza de un porvenir auspicioso. Igualmente, la idea de un porvenir incierto y apocalíptico está contenida en las subjetividades que se transmiten a través de estos medios: «Aún piensan que llegarán al 2060, de esta década no pasará la humanidad» (Hombre).

De manera que cuando los contenidos de los contactos virtuales son de mayor abstracción, se evidencia una idea de futuro más desesperanzador: 


\section{EL FIN DEL MUNDO}

El fin del mundo ya ha durado mucho

Y todo empeora

Pero no se acaba.

\section{FIGURA 11. COVID-19 Y FUTURO DESESPERANZADOR. INSTAGRAM}

Ello es respaldado por interacciones igualmente abstractas: «The world die every day for someone [El mundo muere todos los días por alguien]» (Sexo sin determinar). Como igualmente por alusiones a algo indeterminado que estaría escarmentando el comportamiento de la humanidad: «Quizás ese es el castigo, que no acaba» (Sexo sin determinar). Sin embargo, también se ofrece una salida acorde al mandato neoliberal, que alude a la gestión individual del temor al futuro: «El mundo se acaba cuando uno muere (Hombre).

La presencia del Covid-19 en nuestras sociedades deja de manifiesto el agobio existencial con que las juventudes viven la pandemia, en un territorio que no les ofrece seguridades ni soluciones profundas:

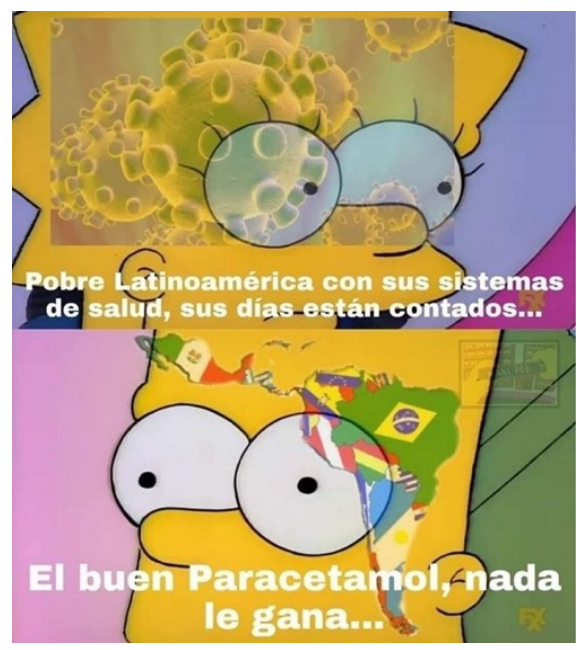

FigurA 12. COVID-19 EN AMÉRICA LATINA. INSTAGRAM 
La desesperanza en el futuro forma parte de las subjetividades presentes en estas interacciones: «na que hacer... nacimos para morir...» (Hombre). El miedo a lo desconocido vivido como indefensión se hace presente en la construcción de estas subjetividades: «cuándo iremos a saber cómo parar esta cuestión del terror...estamos solos!!!!» (Mujer).

La cotidianeidad de los hitos que marcan los cursos de vida juveniles, también son afectados por la pandemia y se viven como pérdida de libertades y angustia:

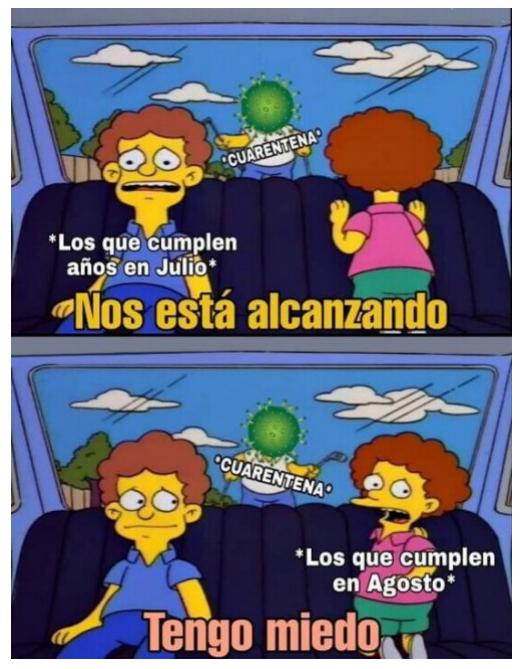

FIGURA 13. COVID-19 Y VIDA COTIDIANA. INSTAGRAM

Las interacciones reflejan tal pérdida de libertad, miedo y agobio: «somos sus esclavos...»(Hombre). Mientras que se clama por protección ante la pandemia: «...y aquí seguimos solos sin que nadie haga na!» (Hombre), y las cotidianeidades se viven en soledad y desesperanza: «No puedo ver a mis abuelos... menos a los weis...» (Hombre).

El temor y agobio existencial continúan en tiempos de pandemia, que, aunque tiene un motivo explícito, este es igualmente desconocido y temido: 


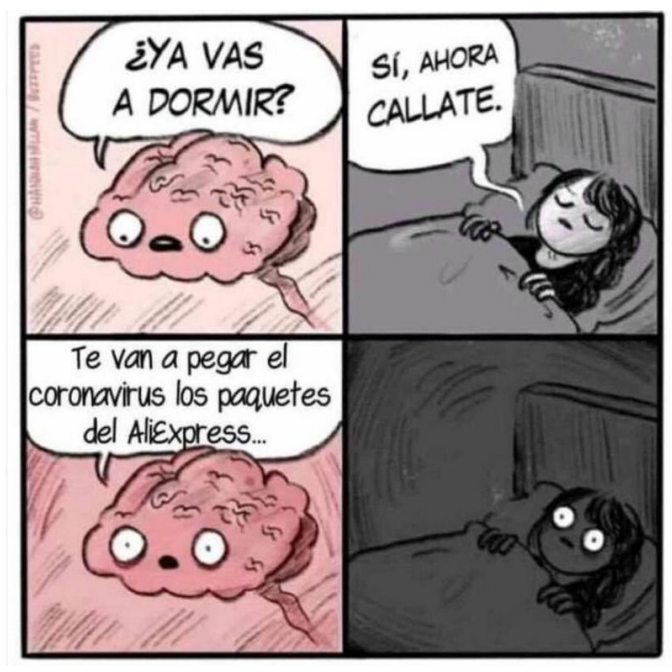

FIGURA 14. COVID-19 Y VIDA COTIDIANA

Las subjetividades están marcadas en la actualidad por el temor a lo que antes era habitual: «ya ni soñar se puede... cada vez peor...» (Mujer). La ironía ante la resignación se hace presente como un signo de estos tiempos: «No sueñe amigue... quédese en el rebaño del corona no ma...» (Hombre).

\section{7. ¿CERCANÍA POLÍTICA O RENTABILIZACIÓN DE SUBJETIVIDADES?}

Las diversas redes que publican contenidos los dirigen a grupos específicos de personas, que compartirían ciertas características, como por ejemplo vivir en algún lugar determinado, estudiar cierta área del conocimiento, estar ligadas específicamente a alguna carrera, entre otras.

Que estos grupos virtuales posean ciertas características tendría concordancia con el criterio de fecundidad, que es un principio necesario para la reproducción y replicación de memes exitosos. Así, una idea puede ser difundida y podría influir en las subjetividades de quienes participan en estas interacciones, con mayor facilidad siempre y cuando dicha idea fuese cercana a los imaginarios 
sociales y culturales de tales personas. Ello, a su vez, potenciaría la conformación de grupos humanos con perfiles determinados y similares, que habitan contextos sociohistóricos específicos, lo que podría, eventualmente, ser puesto al servicio de los gobiernos siempre vigilantes de sus poblaciones, ya sea para fines loables que permitan mejorar sus vidas cotidianas, o para emplear las informaciones allí contenidas, para desarrollar mecanismos de control social y/o policial. De modo que el criterio de fecundidad de los memes y sus consecuencias serían aristas que observar desde las posibilidades de rentabilidad política en futuras investigaciones sobre esta temática.

Desde otra perspectiva, la mutabilidad y dinamismo característico de los memes, que muchas veces se manifiestan a través de la creatividad de las personas al innovar en las formas o situaciones en las que una frase o imagen puede ser utilizada, generarían una concatenación de memes. Es decir, una publicación puede contener respuestas cuyo contenido está constituido por otros memes, produciéndose una nueva unidad discursiva de difusión cultural, que tiene como referencia la situación inicial. De modo que quienes participan de estos contactos virtuales siempre tienen posibilidades de rearticular dichas unidades culturales, dotándolas de otros sentidos, generando narrativas alternativas que podrían llegar a disputar las ideas contenidas en los memes originales. Así, a través de estas interacciones virtuales, hasta las ideas más aceptadas y legitimadas en determinado contexto histórico podrían ser paulatinamente desmontadas en las sociedades contemporáneas. Ello, a su vez, podría ser considerado una forma de resistencia con respecto a aquellos discursos hegemónicos que se articulan a través de los memes de Internet. Por tanto, cabría preguntarnos, ¿qué sucedería si existiera un movimiento social de jóvenes que inste por la producción de contenidos, a través de memes, que auguraran futuros utópicos? ¿Ello sería rentabilizado políticamente, o seguiría siendo solo el miedo y agobio existencial lo que otorga réditos políticos a gobiernos socialmente deslegitimados? 
Por otra parte, luego de esta aproximación a los memes como unidades culturales influyentes en las subjetividades juveniles, es posible sostener que una de sus características principales es que su contenido suele ser de corte humorístico. Es decir, que la reproducción exitosa de una idea también estaría influida por la forma en que es presentada, interviniendo en su fecundidad. En el caso específico de las interacciones virtuales que transmiten concepciones pesimistas en torno al futuro, las ideas sobre agobio, incertidumbre o miedo en la cotidianeidad de la vida en el actual contexto sociosanitario, cuando tales memes no presentan el elemento humorístico, tienden a ser rechazadas o criticadas. Ello podría ser explicado a través de la obligatoriedad que la cultura exitista impone sobre las personas, en que el miedo, agobio o pesimismo son emociones socialmente validadas solo cuando se trata de «ser voz de los sin voz», es decir, cuando la idea transmitida está circunscrita a fenómenos que afectan a quienes requieren de auxilios. De allí que el humor se constituya, entonces, en una vía para expresar aquello que está vedado en las sociedades neoliberales de impronta exitista.

Del mismo modo, la concreción /abstracción de los mensajes transmitidos confluirían a la constitución de sujetas/sujetos «sujetados» y dependientes de las formas en que el poder allí se manifiesta. Puesto que cuando una publicación presenta una imagen o contenido explícito y directo es menos aceptada, o menos replicada por la comunidad de interactuantes virtuales, que cuando se trata de mensajes de un mayor nivel de abstracción. Ello podría estar en directa relación con que el agobio, la incerteza y el miedo son mayores cuanto más inespecífico sea su origen. Por tanto, frente a mensajes cuyo nivel de concreción es muy alto, quienes participan de estos intercambios virtuales deslegitiman tal miedo, incertidumbre o agobio como una emoción válidamente transmitible.

Entretanto, a partir del acercamiento a esta temática es posible sostener que los memes, como unidades culturales ampliamente difundidas, estarían 
confluyendo en la construcción de subjetividades, que se gestionan de modo individual conforme a los mandatos de las sociedades neoliberales y exitistas, puesto que se observan ciertos consensos sobre las ideas de agobio existencial, futuro incierto e incertezas. Aun cuando a partir de esta revisión no sea posible determinar con exactitud el modo en que el sexo y edad de cada persona participante de estas interacciones virtuales mediatiza las subjetividades con las que participa de estas comunidades, sí es posible estimar que el creciente número de interacciones de este tipo y la evidencia de relaciones de género y etarias allí contenidas se convertirían en posibilidades reales de rentabilizar políticamente estas emociones, dado que estos memes, entre muchas otras fuentes de información disponibles en la web, se constituyen en insumos que permiten nutrir intervenciones discursivas que intentan obtener dividendos políticos de las rupturas cotidianas, y los abismos de incertezas y agobios y miedos al futuro con que las juventudes han vivido la pandemia en Chile en particular, y en Latinoamérica en general.

Desde otra perspectiva, también cabría discutir la idea respecto a que el miedo, pesimismo e incertezas con que se significa el futuro, como asimismo el agobio existencial, contienen cierto grado de univocidad de emociones con los que los memes de esta naturaleza contribuyen a sedimentar la idea de que en las actuales sociedades, efectivamente ha habido un cambio en el modo de integración social, pasando de la promesa de ascenso a la amenaza de exclusión; retroalimentando la sensación de vacío y ambivalencias social, en que la pluridimensionalidad del futuro es vista más bien como una amenaza que como una oportunidad de apertura, mental, cultural, política y social. A ello se suma la idea, también ampliamente expandida en las sociedades neoliberales actuales, referida a que una «vida mejor» está desempotrada de la noción de futuro, instalándose en su lugar pesimismos, miedos e incertezas en el porvenir y, por tanto, agobios. Todo ello sería políticamente rentabilizado, tanto por los conglomerados imperantes, como por los Gobiernos de turno, que encuentran allí 
nuevas formas discursivas, vinculadas a la protección de las personas, frente a aquello que es vivido en la cotidianeidad como algo inmenso, desconocido y, por lo tanto, incierto, para legitimar su poder, puesto que en el contexto del Covid19 ello ha sido deslegitimado por la desconexión entre las políticas implementadas y las necesidades y sentires de las personas. La pregunta que cabría hacernos entonces es si ¿estas formas de gestión del miedo al futuro, agobios e incertidumbres, como preocupación central de los Gobiernos de turno, son susceptibles de ser comparados en sus contenidos discursivos con las subjetividades que los memes contribuyen a construir en estas interacciones virtuales?

\section{Conclusiones}

A partir del análisis de los datos empíricos recolectados es posible sostener que los memes como unidades culturales, a través de sus discursos, construyen subjetividades que cumplen una doble función social: por una parte, serían medios para la expresión y canalización emocional en sociedades con culturas exitistas, en que la gestión de emociones socialmente disonantes debe ser individual, más aún cuando tales sociedades están mediadas por el Covid-19 y la virtualización de las relaciones sociales. Pero desde otra perspectiva, los memes serían recursos que potenciarían la manipulación y control de las poblaciones por parte de la clase política, que rentabilizaría tales emociones.

En el caso de las juventudes chilenas, la rentabilización política del agobio existencial y del temor al futuro, expresados a través de distintas aplicaciones y redes sociales, se evidencia, por ejemplo, en que las ideas de oportunidades, libertades, temores, angustias, sueños y soledad están recurrentemente presentes en los memes con los que las personas jóvenes intersubjetivamente se comunican, por tanto, son elementos centrales de sus 
cotidianeidades y expresión de sus miedos. A la vez, que corresponden a conceptos centrales empleados durante el tiempo de la campaña hacia la presidencia del actual líder del Gobierno de Chile. La rentabilización política de ello se demostraría en que tales conceptos, empleados en tiempos de captación de votantes, representan ambivalencias, vacíos e incertezas para el mundo juvenil, constituyéndose en temores expresados como miedo al futuro, siendo un elemento válido para la mayoría de las personas pertenecientes a ese rango etario. En tales circunstancias, dichas nociones empleadas como expresión de cercanía a las cotidianeidades juveniles y a sus entornos, y traducidas en promesas simbólicas, como contenidos latentes de campaña, podrían permear las elecciones políticas de aquellas personas en cuyas subjetividades esté la necesidad de sentir que, en un mundo inabarcable, sus inquietudes son interpretadas por quienes están a cargo de ejercer el poder en sus territorios.

En consecuencia, los discursos contenidos en los memes como unidades culturales se convierten en campos en disputa para las ciencias sociales contemporáneas, como disciplinas cuya centralidad es el desarrollo de reflexividades críticas que potencien la desnaturalización de ideas y prácticas hegemónicas, excluyentes y coactivas. Ello es especialmente relevante en sociedades neoliberales como las actuales, en que se comienza a evidenciar, a través de estos contactos virtuales, que el miedo, agobio e incertezas, exacerbados en el contexto de pandemia, se estarían constituyendo en principios cuya validez es superior a otros elementos generadores de consensos sociales, ya que las subjetividades expresadas a través de estas unidades virtuales se basan en conceptos de miedo, tales como inclusión/exclusión; bienestar/malestar; éxito/fracaso; seguridad/inseguridad, entre otras dicotomías que evidencian temor y agobio, frente a un mundo vivenciado como inabarcable. En tal sentido, cabría preguntarnos ¿en qué medida los ejes discursivos centrales en el actual contexto de pandemia, referidos al miedo al futuro y el agobio existencial, serían funcionales al acallamiento de las juventudes en nuestros países? Más aún si 
consideramos el rol protagónico que han tenido en los procesos de cambios sociales de las últimas décadas.

RECIBIDO: 30 DE JUNIO DE 2021

ACEPTADO: 13 DE AGOSTO DE 2021

\section{BibLIOGRAFÍA}

ApredA, G. (2004). La concepción del sujeto en Michel Foucault. Recuperado el 18 de mayo de 2020 de: http://borromeo.kennedy.edu.ar/Artculos/SujetofoucaultApreda.pdf

BAUMAN, Z. (2017). Retrotopía. Editor digital: Titivillus . (2008). Tiempos líquidos: Vivir en una época de incertidumbre. México, D. F.: Tusquest.

Beck, U. (2006). Hijos de la libertad. México, D. F.: Fondo de Cultura Económica.

. (2002). La sociedad del riesgo. Hacia una nueva modernidad. Barcelona: Paidós.

Bude, H. (2014). La sociedad del miedo. Editor digital: XcUiD. WWW.Lectulandia.com

DAWKINS, R. (1985). El gen egoísta: las bases biológicas de nuestra conducta. Barcelona: Salvat.

FoucAult, M. (1994). La ética del cuidado de uno mismo como práctica de la libertad. En La hermenéutica del sujeto. Madrid: La Piqueta. . (1992). Microfisica del poder. Madrid: La Piqueta. . (1979). La arqueología del saber. México, D. F.: Siglo XXI.

GARCÍA, D. (2014). Las imágenes macro y los memes de internet: posibilidades de estudio desde las teorías de la comunicación. Paakat: Revista de 
tecnología $y$

sociedad.

https://www.redalyc.org/pdf/4990/499051555007.pdf

GIDDENS, A. (1996). Las consecuencias de la modernidad. Madrid: Alianza.

Guattari, F. (1998). El devenir de la subjetividad. Santiago de Chile: Dolmen.

Guattari, F. y Rolnik, S. (2006). Microfisica. Cartografías del deseo. Madrid: Traficantes de Sueños.

Halligan, B. y SHAH, D. (2021). Tendencias en redes sociales 2021.

Recuperado el 16 de agosto de 2021 de:

https://f.hubspotusercontent00.net/hubfs/53/00-OFFERS-

HIDDEN/\%5BSPANISH\%5D\%20SMT\%202021/Tendencias\%20Rede s\%20Sociales $\% 202021$.pdf?utm campaign=SPANISH $\% 20$ -

$\%$ 20Social\%20Media\%20Trends\%202021\&utm_medium=email\&utm_ content $=97554316 \& u t m \_s o u r c e=h s \_$automation

KEMP, S. (2021). Digital 2021: Global digital overview. Recuperado el 16 de agosto de 2021 de: https://datareportal.com/reports/digital-2021-globaloverview-report

Laca Arocena, F. (2011). Retorno a Hobbes: Hacia una cultura del miedo. Estudios sobre las Culturas Contemporáneas, XVII(33), 9-22. https://dialnet.unirioja.es/servlet/articulo? codigo $=3765526$

MINSAL (2020). Presidente Piñera presenta programa SaludableMente. Recuperado el 18 de julio de 2021 de: https://www.minsal.cl/presidentepinera-presenta-programa-saludablemente/

Vota Inteligente (2018). Programa de gobierno de Sebastián Piñera. Recuperado el 18 de julio de 2021 de: http://programa.sebastianpinera.cl/ 